\title{
Stability-indicating methods for the determination of olanzapine in presence of its degradation products
}

\author{
Lobna Abd El Aziz Hussien a, Maha Farouk Abdel Ghani a, \\ Amal Mahmoud Abo El Alamein ${ }^{\mathrm{b}}$ and Ekram Hany Mohamed c,* \\ a Analytical Chemistry Department, Faculty of Pharmacy, Ain Shams University, Abbassia, Cairo, 11381, Egypt \\ b Analytical Chemistry Department, Faculty of Pharmacy, Cairo University, Cairo, 12613, Egypt \\ c Analytical Chemistry Department, Faculty of Pharmacy, British University in Egypt, Sherouk, 11837, Egypt
}

*Corresponding author at: Analytical Chemistry Department, Faculty of Pharmacy, British University in Egypt, Sherouk, 11837, Egypt. Tel.: +20.2.01093725602. Fax: +20.2.687.5879. E-mail address: ekram.hany@bue.edu.eg (E.H. Mohamed).

\section{ARTICLE INFORMATION}

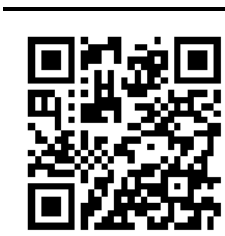

DOI: 10.5155 /eurjchem.5.2.311-320.951

Received: 22 October 2013

Received in revised form: 06 December 2013

Accepted: 25 December 2013

Online: 30 June 2014

\section{KEYWORDS}

\section{Olanzapine}

Q-absorbance

Chemometrics

Dual wavelength

Bivariate calibration

Derivative spectrophotometer

\section{Introduction}

Olanzapine; 2-methyl-4-(4-methyl-1-piperazinyl)-10 Hthieno[2,3-b][1,5]benzodiazepine (Figure 1) is a second-generation antipsychotic drug, used in treatment of schizophrenia and prescribed mainly for patients with prominent agitation and insomnia [1]. OLA also may help with weight gain in anorexia nervosa [1]. The exact mechanism by which OLA exerts its antipsychotic effect is unknown. However, this effect may be mediated through a combination of dopamine and serotonin antagonism [1]. Olanzapine is metabolized primarily through oxidation mediated by cytochrome P450 (CYP) enzymes and by direct glucuronidation. The two major metabolites, $10-\mathrm{N}$-glucuronide and $4^{\prime}-\mathrm{N}$-desmethyl olanzapine, are not pharmacologically active at the plasma levels achieved [1]. OLA could be determined by several analytical techniques, titrimetric methods [2-4], spectroscopic methods including colorimetric [5-15], U.V. spectrophotometric [16-18], and fluorimetric [18] methods. OLA can also be determined by electrochemical methods [17,18], capillary electrophoresis [19], and thin layer chromatography [20-24]. High performance liquid chromatographic [HPLC] methods were widely used for analysis of OLA in pure form [25-57]. OLA was also successfully determined using gas chromatography [58]. Chemometrics was applied for simultaneous determination of OLA and Fluoxetine [59].

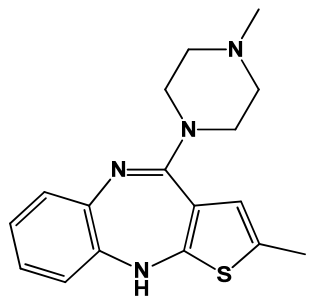

Figure 1. Chemical structure of intact olanzapine. 


\section{Experimental}

\subsection{Instrumentation}

A double beam UV-VIS spectrophotometer (UV-1800, Japan) connected to IBM compatible computer. The bundled software is UV probe software version 2.32 (Shimadzu) and the spectral bandwidth was $0.1 \mathrm{~nm}$. The absorption spectra were carried out using $1 \mathrm{~cm}$ quartz cells. The chemometric calculations were performed in Matlab for Windows-version 7 Mathworks Inc.2004. The PLS procedure was taken from PLS Toolbox 2.1, Eigenvector Research Inc. 2001 created by B.M. Wise, N.B. Gallagher for use with Matlab.

\subsection{Materials and reagents}

All chemicals were of analytical grade, the solvents were of spectroscopic grade.

OLA was kindly supplied by Egyptian International Pharmaceutical Industries Company (Eipico) $10^{\text {th }}$ of Ramadan City, Egypt. Its purity was $100.45 \pm 0.30 \%(n=5)$ according to the reported method [16].

Olanza ${ }^{\circledR 5} \mathrm{mg}$ tablets, labeled to contain $5 \mathrm{mg}$ of OLA per tablet manufactured by Egyptian International Pharmaceutical Industries Company (Eipico) 10th of Ramadan City, Batch No.1821007 and purchased from the local market.

Sodium hydroxide, hydrochloric acid (Adwic-Cairo, Egypt), methanol (Analar-Germany).

\subsection{Standard solutions of the intact OLA}

Stock solution: A standard stock solution of OLA was prepared by accurately transferring $100 \mathrm{mg}$ of pure drug into a $100 \mathrm{~mL}$ volumetric flask, dissolving in $20 \mathrm{~mL}$ methanol and then the volume was completed to the mark with the same solvent to provide standard stock solution containing 1.00 $\mathrm{mg} / \mathrm{mL}$.

Working solution: OLA working solution $(0.02 \mathrm{mg} / \mathrm{mL})$ was prepared by transferring $2 \mathrm{~mL}$ of the standard stock solution into $100 \mathrm{~mL}$ volumetric flask and then the volume was completed to the mark with methanol.

\subsection{Preparation of standard solution of acidic and alkaline degraded OLA}

$50 \mathrm{mg}$ of OLA was mixed with $25 \mathrm{~mL}$ of $2 \mathrm{M}$ hydrochloric acid one time and $4 \mathrm{M}$ sodium hydroxide another time and refluxed for 6 hours. The solutions were cooled, neutralized with $2 \mathrm{M}$ aqueous sodium hydroxide and $4 \mathrm{M}$ aqueous hydrochloric acid respectively, till $\mathrm{pH}=7$, transferred to $50 \mathrm{~mL}$ volumetric flasks and diluted to the mark with methanol $(1.00$ $\mathrm{mg} / \mathrm{mL}$ ). Aliquot portions of these solutions were diluted with methanol to prepare working standard solutions of 0.02 $\mathrm{mg} / \mathrm{mL}$.

Complete degradation was confirmed was confirmed by the reported HPLC method, using inertsil $\mathrm{C}_{18}$ column $(5 \mu \mathrm{m}, 150$ $\mathrm{mm} \times 4.6 \mathrm{~mm}$ i.d). The mobile phase was a mixture of $9.5 \mathrm{mM}$ sodium dihydrogen phosphate $(\mathrm{pH}$ adjusted to $6.8 \pm 0.1$ with triethylamine), acetonitrile and methanol (40:30:30, by volumes) and UV detection at $225 \mathrm{~nm}$ [46].

The previously prepared solutions were evaporated to dryness. Then the degradation products were extracted with multiple fraction of methanol $(3 \times 10 \mathrm{~mL})$. Then the extract was evaporated at room temperature and the degradation products were collected. The degradation products powder was elucidated by IR and mass spectrometry.

\subsection{Procedures}

2.5.1. Construction of calibration curves for $D^{1}$ and $D^{2}$ spectrophotometric method
Accurately measured volumes of intact OLA working solution $(0.02 \mathrm{mg} / \mathrm{mL})$ were transferred into a series of $10 \mathrm{~mL}$ volumetric flasks and diluted to the mark with methanol to obtain concentrations from 0.002 to $0.02 \mathrm{mg} / \mathrm{mL}$. The $\mathrm{D}^{1}$ and $\mathrm{D}^{2}$ spectra of each solution was recorded using $\Delta \lambda=8$ and scaling factor $=100$. For determination of OLA in presence of its acidic degradation products a calibration curve was obtained by plotting the peak amplitudes of $\mathrm{D}^{1}$ at $261.2 \mathrm{~nm}$ versus the corresponding drug concentrations. While for OLA determination in presence of its alkaline degradation products the peak amplitudes of $\mathrm{D}^{1}$ and $\mathrm{D}^{2}$ at 260.6 and $239.9 \mathrm{~nm}$ were recorded, respectively (corresponding to zero-crossing of the degradation product) versus the corresponding concentrations of drug, and regression equations were computed.

\subsubsection{Construction of calibration curves of $\left(D D^{1}\right)$ spectrophotometric method}

Different aliquots of intact OLA working solution $(0.02$ $\mathrm{mg} / \mathrm{mL}$ ) were accurately transferred into a series of $10 \mathrm{~mL}$ volumetric flasks and diluted to the mark with methanol to obtain concentrations from 0.002 to $0.02 \mathrm{mg} / \mathrm{mL}$. The $\mathrm{DD}^{1}$ curves were recorded at $\Delta \lambda=8$ and scaling factor $=10$. The absorption spectra of these solutions were divided by the absorption spectrum of $0.004 \mathrm{mg} / \mathrm{mL}$ of the acidic and alkaline degradation products separately (as divisors). The obtained ratio spectra were then differentiated with respect to wavelength. The peak amplitudes at 267.9 and $251.6 \mathrm{~nm}$ were recorded for the determination of OLA in presence of its acidic and alkaline degradation products, respectively. The calibration curves representing the relationship between the measured amplitudes and the corresponding concentrations of the drug were constructed and the regression equations were computed.

\subsubsection{Construction of calibration curves for $\mathrm{pH}$-induced difference method}

Accurately measured volumes of intact OLA working solution $(0.02 \mathrm{mg} / \mathrm{mL})$ were transferred into two sets of $10 \mathrm{~mL}$ volumetric flasks, diluting the first set to the mark with $0.1 \mathrm{M}$ $\mathrm{NaOH}$ and the second set with $0.1 \mathrm{M} \mathrm{HCl}$ to obtain concentration range from 0.002 to $0.02 \mathrm{mg} / \mathrm{mL}$. The Zero-order spectrum of each dilution was recorded against its corresponding blank. The previous spectra of each dilution were computed, to give $(\Delta \mathrm{A})$ spectra. The peak amplitudes of $(\triangle \mathrm{A})$ spectra were recorded at 240 and $247.9 \mathrm{~nm}$ for determination of ((OLA) in presence of its acidic and alkaline degradation products respectively (Corresponding to zerocrossing of the degradation products) and plotted against the corresponding concentrations of OLA. The regression equations were then computed.

\subsubsection{Construction of calibration curves for Q-analysis (absorption ratio) method}

Accurately measured volumes of intact OLA and its acidic degradation products working solutions were transferred separately into a series of $10 \mathrm{~mL}$ volumetric flasks and diluted to the mark with methanol to obtain concentrations from 0.002 to $0.02 \mathrm{mg} / \mathrm{mL}$. The Zero-order spectrum of each dilution was recorded against methanol as a blank. The absorbance of OLA and its acidic degradates were measured at 296.3 and $271 \mathrm{~nm}$ for each dilution separately. Then the absorbance at the selected wavelengths was plotted against the corresponding concentrations and the regression equations were then computed. Absorptivity coefficients of OLA and its acidic degradation products were determined at both selected wavelengths; the absorption equation was then formed. The concentration of the drug of interest is calculated from the equation. 


\subsubsection{Construction of calibration curve for dual wave length method}

Accurately measured volumes of intact OLA working solution $(0.02 \mathrm{mg} / \mathrm{mL})$ were transferred into a series of $10 \mathrm{~mL}$ volumetric flasks and diluted to the mark with methanol to obtain concentrations from 0.002 to $0.02 \mathrm{mg} / \mathrm{mL}$. The Zeroorder spectrum of each dilution was recorded against methanol as blank. The absorbance of OLA was measured at 270 and $246.3 \mathrm{~nm}$ for each dilution separately. Then the difference between the absorbance at the selected wavelengths was calculated, plotted against the corresponding concentrations of the drug and the regression equation was then computed.

\subsubsection{Construction of calibration curve for bivariate spectrophotometric method}

Accurately measured volumes of OLA and its acidic degradation products working solutions were transferred separately into a series of $10 \mathrm{~mL}$ volumetric flasks and diluted to the mark with methanol to obtain concentrations from 0.002 to $0.02 \mathrm{mg} / \mathrm{mL}$ for both OLA and its acidic degrades. The Zeroorder spectrum of each dilution was recorded against methanol as blank. The absorbance of OLA and its acidic degradation products were measured at 229 and $245 \mathrm{~nm}$ for each dilution separately. Then the absorbance values at the selected wavelengths were plotted against the corresponding concentrations and the regression equations were then computed.

\subsubsection{Multivariate calibration technique (Chemometric)}

(a) Construction of training set-Different mixtures of OLA and its acidic degradation products were prepared by diluting different volumes of their working standard solutions into 10 $\mathrm{mL}$ volumetric flask and completing to the final volume with methanol. The absorbance of these mixtures was measured between $240-370 \mathrm{~nm}$ at $1 \mathrm{~nm}$ interval with respect to a blank of methanol. The composition of the samples was randomly designed according to five level calibration design [60] in order to obtain non correlated concentration profiles and this calibration design prepared to obey Beer's law.

(b) Constructing the models-To build the CLS model, feed the computer with absorbance and concentration matrices for training set. Carry out the calculations to obtain the "K" matrix. For the PCR and PLS models, use the training set absorbance and concentration matrices together with PLS-Toolbox 2.0 software for the calculations.

(c) Construction of the validation set. Prepare different nine mixtures of OLA and its acidic degradation products by transferring different volumes of their working standard solutions into a series of $10 \mathrm{~mL}$ volumetric flasks and complete to volume with methanol. Apply the developed models to predict the concentration of OLA in each mixture.

\subsubsection{Laboratory prepared mixtures}

Solutions containing different ratios of OLA and up to $60 \%$ of its acidic and $60 \%$ of its alkaline degradation products were prepared to obtain mixture solutions of intact drug and both its degradation products separately.

\subsubsection{Application to pharmaceutical preparation}

Ten tablets were accurately weighed and finely powdered. A portion equivalent to $50 \mathrm{mg}$ of OLA was weighed, sonicated in $20 \mathrm{~mL}$ methanol and filtered into $50 \mathrm{~mL}$ volumetric flask. The residue was washed three times each with $8 \mathrm{~mL}$ methanol and completed to the mark with the same solvent. Aliquots (according to linearity) was transferred to $10 \mathrm{~mL}$ volumetric flasks and diluted with methanol. The general procedures were followed and the concentration of OLA was calculated from its corresponding regression equation.

\section{Results and discussion}

The International Conference on Harmonization (ICH) guideline entitled "stability testing of new drugs substances and products" requires the stress testing of new substances and products, also requires the stress testing to be carried out to elucidate the inherent stability, characteristics of the active substance [61]. An ideal stability indicating method is one that quantifies the standard drug alone and also resolves its degradation products.

The structures of the intact drug, acidic and alkaline degradation products were elucidated by IR and mass spectrometry. The major acidic degradation product suggested in acidic conditions is 2-[(2-aminophenyl)amino]- $N$-ethenyl$\mathrm{N}, 5$-dimethylthiophene-3-carboxamide as presented in (Figure $2)$. While in case of alkaline conditions, 2-[(2-aminophenyl) amino]-5-methylthiophene-3-carboxylic acid (I) and 4-methyl piperazin-1-amine (II) are suggested to be the major degradation product (Figure 3).
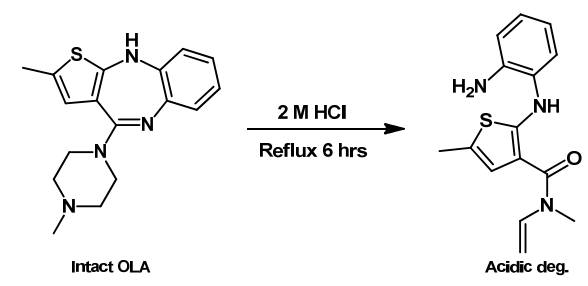

Figure 2. Scheme for acidic degradation of OLA.

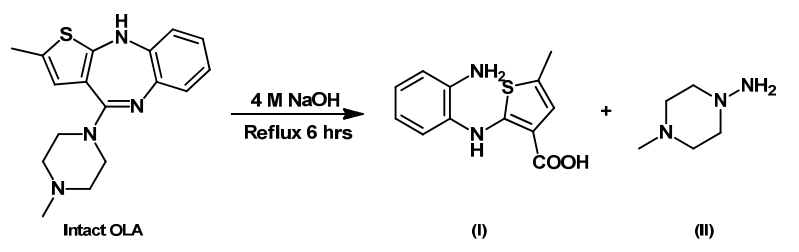

Figure 3. Scheme for alkaline degradation of OLA.

The IR spectrum of OLA showed a characteristic band at $3217.7 \mathrm{~cm}^{-1}$ indicating the presence of $\mathrm{NH}$ group, and a band at $2932.9 \mathrm{~cm}^{-1}$ indicating the presence of Alkane $\mathrm{C}-\mathrm{H}$ bonds. While IR spectrum of the acidic degradates showed a characteristic broad band at $3541.5 \mathrm{~cm}^{-1}$, indicating the presence of $\mathrm{OH}$ group and another two characteristic bands at 3483.8 and $3398.2 \mathrm{~cm}^{-}$ 1 indicating the presence $\mathrm{NH}_{2}$ group while the appearance of a band at $1639.2 \mathrm{~cm}^{-1}$ suggest the presence of $\mathrm{C}=0$ group. The IR spectrum of the alkaline degradation products showed characteristic broad band at $3439.1 \mathrm{~cm}^{-1}$, indicating the presence of $\mathrm{OH}$ group and a band at $2360.6 \mathrm{~cm}^{-1}$ suggesting the presence of $\mathrm{C} \equiv \mathrm{N}$ group, and a band at $1634.0 \mathrm{~cm}^{-1}$ suggest the presence of $\mathrm{C}=0$ group.

While the mass spectrum showed characteristic peaks at $\mathrm{m} / \mathrm{z} 287.11$ and 45 in case of acidic degradation and at 248.06 and 115.11 in case of alkaline degradation.

The major acidic degradation product suggested is $2-[(2-$ aminophenyl)amino]- $N$-ethenyl- $N, 5$-methylthiophene-3-carbox amide (I) and dimethylamine (II). While in case of alkaline degradation, 2-[(2-aminophenyl)amino]-5-methylthio-phene3-carboxylic acid (I) and 4-methylpiperazin-1-amine (II) are suggested to be the major degradation product .

The focus of the present work was to develop accurate, specific, reproducible and sensitive stability indicating methods for the determination of OLA in pure form and in 
pharmaceutical formulation in the presence of acidic and alkaline degradation products.

The zero-order absorption spectrum of OLA and its acidic and alkaline degradation products showed sever overlapping (Figure 4 and 5) which interfere with the direct determination of OLA.

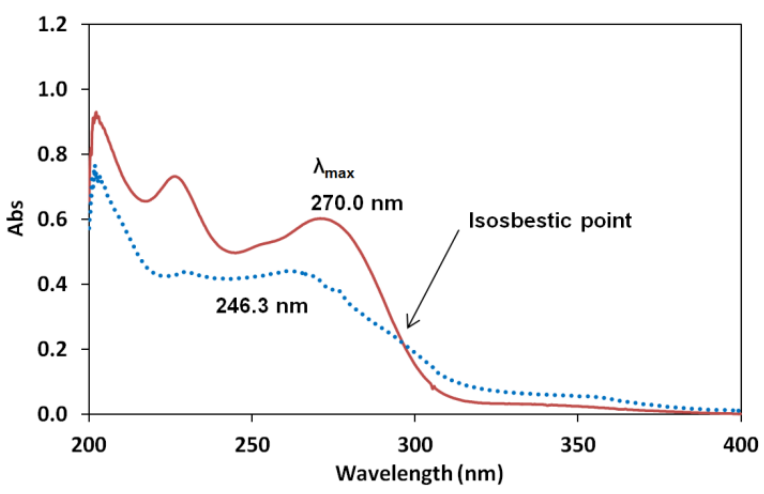

Figure 4. Zero order spectra of OLA (__ ) and acidic degradation products (...) $(10 \mathrm{ug} / \mathrm{mL}$ each) using methanol as a solvent.

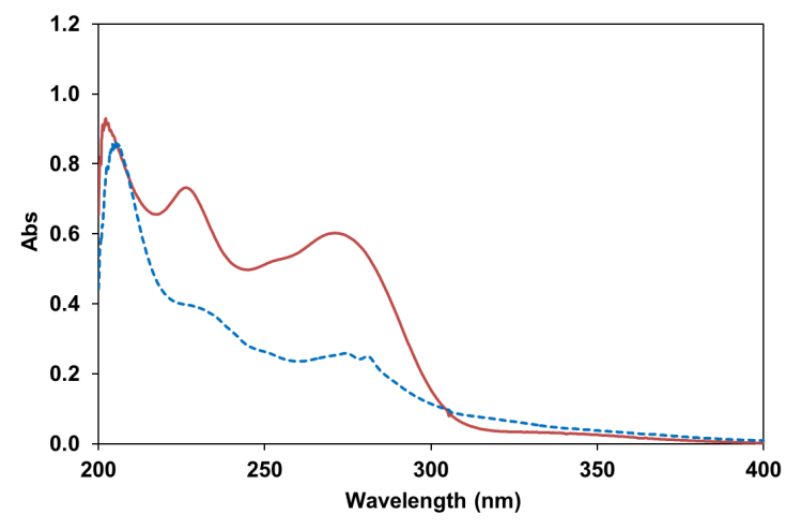

Figure 5. Zero order spectra of OLA (__ ) and of alkaline degradation products (---) $(10 \mathrm{ug} / \mathrm{mL}$ each) using methanol as a solvent.

\subsection{Derivative spectrophotometry}

A rapid, simple and low cost spectrophotometric methods based on measuring the peak amplitude of $\mathrm{D}^{1}$ at $261.2 \mathrm{~nm}$ (Figure 6) and $260.6 \mathrm{~nm}$ (Figure 7) for determination of OLA in presence of its acidic and alkaline degradation products respectively and also measuring the peak amplitude of $\mathrm{D}^{2}$ at $239.9 \mathrm{~nm}$ (Figure 8) for determination of OLA in presence of its alkaline degradation products (corresponding to zero crossing of the degradation products) were developed with good selectivity without interference of its acidic and alkaline degradation products over concentration range from 2-20 $\mathrm{ug} / \mathrm{mL}$.

In order to optimize $\mathrm{D}^{1}$ and $\mathrm{D}^{2}$ methods, different smoothing and scaling factors were tested, where a smoothing factor $\Delta \lambda=8$ and scaling factor $=100$ showed a suitable signal to noise ratio and the spectra showed good resolutions.

The proposed methods are valid for the determination of OLA in presence of its acidic and alkaline degradation products in different laboratory prepared mixtures.

\subsection{DR ${ }^{1}$ method}

In order to improve the selectivity of the analysis of OLA in presence of its acidic and alkaline degradation products DR ${ }^{1}$ method was established.

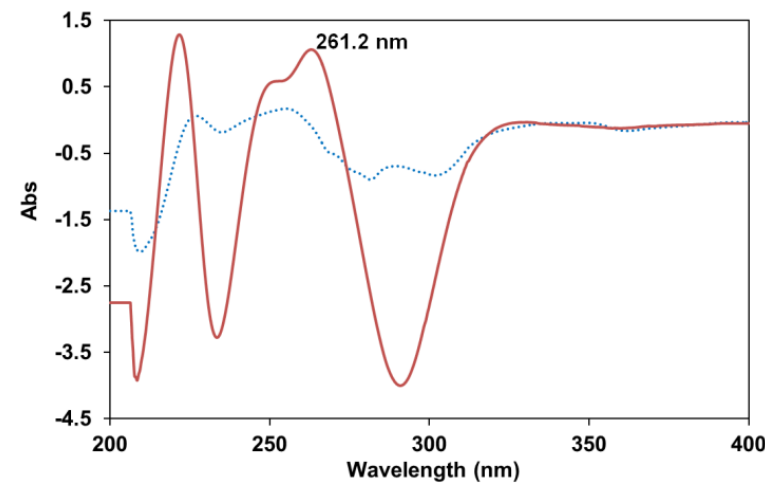

Figure 6. First derivative absorption spectra of $10 \mathrm{ug} / \mathrm{mL}$ of OLA (_) and 10 $\mathrm{ug} / \mathrm{mL}$ of acidic degradation products (....) using methanol as a solvent.

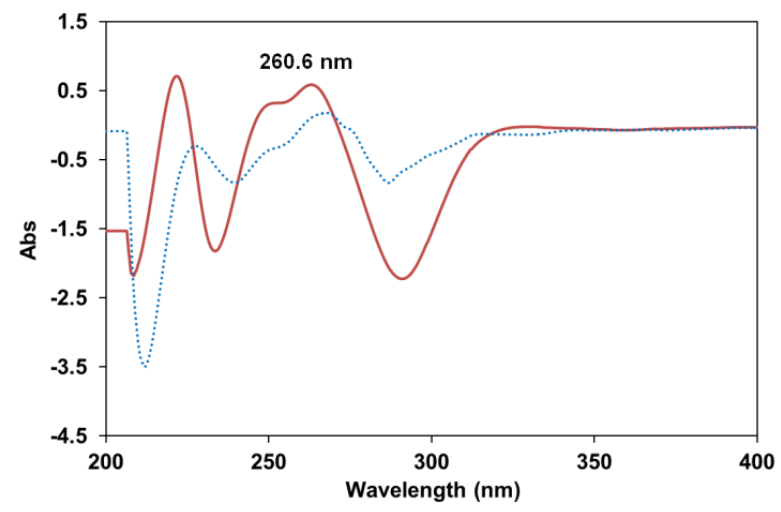

Figure 7. First derivative absorption spectra of $10 \mathrm{ug} / \mathrm{mL}$ of OLA (__) and 10 $\mathrm{ug} / \mathrm{mL}$ of alkaline degradation products (...) using methanol as a solvent.

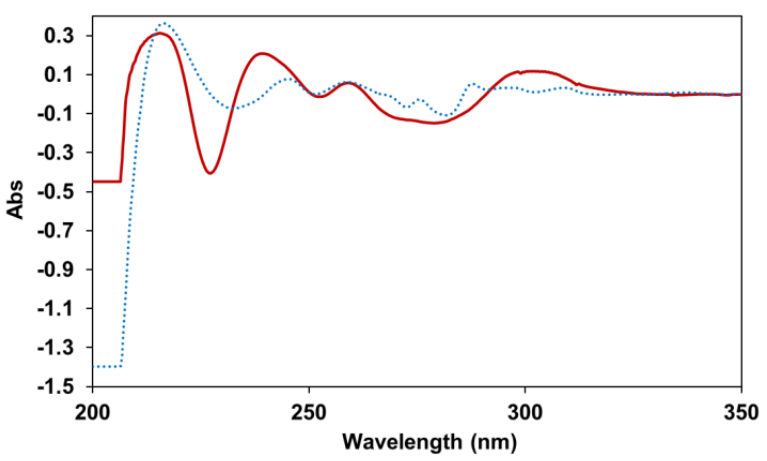

Figure 8. Second derivative absorption spectra of $10 \mathrm{ug} / \mathrm{mL}$ of OLA (__) and $10 \mathrm{ug} / \mathrm{mL}$ of its alkaline degradation products (...) using methanol as a solvent.

The main advantage of the method is that the whole spectrum of interfering substance is cancelled [62]. Accordingly, the choice of the wavelength selected for calibration is not critical as in $\mathrm{D}^{1}$ or $\mathrm{D}^{2}$ derivative method.

In order to optimize $\mathrm{DR}^{1}$ method for determination of OLA in presence of its degradation products, it is necessary to test the influence of the variables: divisor concentration, smoothing and scaling factors.

Several divisor concentrations of the acidic and alkaline degradates were tried, the best results was obtained when using $0.004 \mathrm{mg} / \mathrm{mL}$ of both degradation products as divisors. Different smoothing and scaling factors were also tested where a smoothing factor $\Delta \lambda=8 \mathrm{~nm}$, and scaling factor $=10$ were suitable to enlarge the signals of OLA to facilitate its measurement and to diminish error in reading the signal. 
$\mathrm{DR}^{1}$ values showed good linearity and reproducibility at 267.9 and $251.6 \mathrm{~nm}$ without interference from its acidic and alkaline degradation products respectively (Figure 9 and 10).

Linearity of the peak amplitudes of the $\mathrm{DR}^{1}$ curves at both wavelengths was obtained in range $(0.002-0.02 \mathrm{mg} / \mathrm{mL})$.

The method was checked by analysis of laboratory prepared mixtures of OLA and its acidic and alkaline degradation products in different ratios.

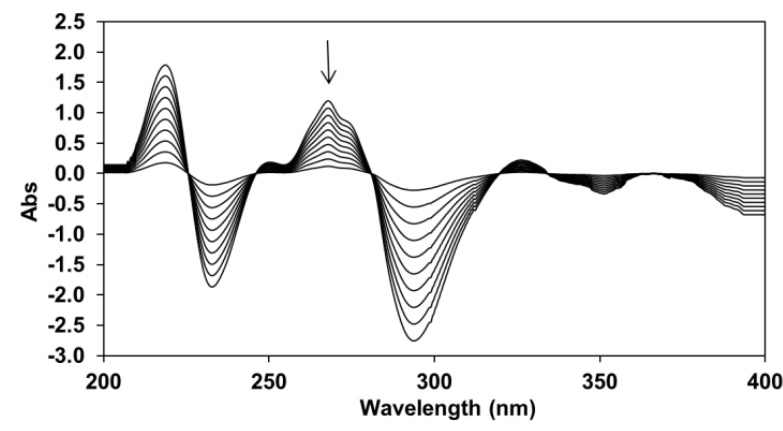

Figure 9. First derivative ratio spectra of different concentrations of OLA (2$20 \mathrm{ug} / \mathrm{mL}$ ) using $4 \mathrm{ug} / \mathrm{mL}$ acidic degradation products as a divisor in methanol.

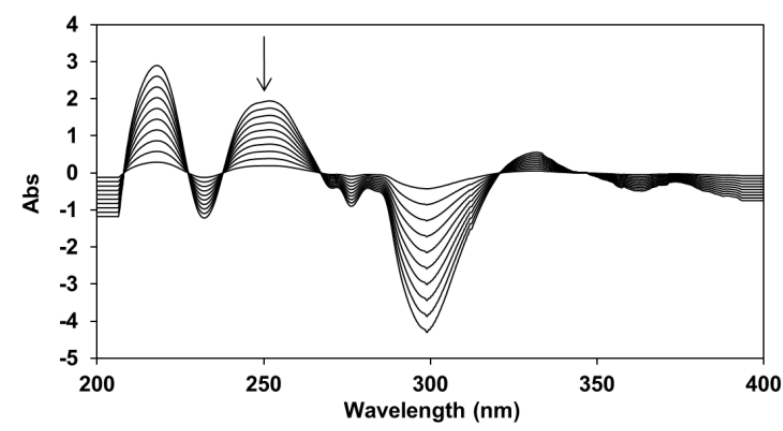

Figure 10. First derivative ratio spectra of different concentrations of OLA $(2-20 \mathrm{ug} / \mathrm{mL}) \mathrm{using} 4 \mathrm{ug} / \mathrm{mL}$ alkaline degradation products as a divisor in methanol.

\section{3. pH-Induced difference $(\Delta A)$ technique}

The most basic nitrogen atoms of OLA located in the piperazine ring are easily protonated resulting in considerable increase in the angle between planes of OLA aromatic rings (benzene and thiophene). Rotation of the piperazine ring and change in its conformation from twist to boat leads to change in the spectral characteristics of OLA upon protonation [63]. Owing to this property, OLA was determined in presence of its acidic and alkaline degradation products, in raw materials and in pharmaceutical formulation, using $\mathrm{pH}$-induced difference technique.

The absorption spectra of OLA in $0.1 \mathrm{M}$ sodium hydroxide and in $0.1 \mathrm{M}$ hydrochloric acid are presented in (Figure 11). OLA could be quantitatively determined at $240 \mathrm{~nm}$ and 247.9 $\mathrm{nm}$ in presence of its acidic and alkaline degradation products, respectively (zero crossing point) without interference from its degradation products, (Figure 12 and 13).

\subsection{Q-analysis (absorption ratio) method}

Absorbance ratio method uses the ratio of absorbances at two selected wavelengths [64], one of which is an isosbestic point and other being the $\lambda$-max of OLA. From the overlain spectrum of the drug and its degradation products, $296.3 \mathrm{~nm}$ (isoabsorptive point) and $271 \mathrm{~nm}$ ( $\lambda_{\max }$ of OLA) were selected for the determination of OLA in presence of its acidic degradation products.

Linear calibration curves were obtained in the range (2-20 $\mathrm{ug} / \mathrm{mL}$ ) for both intact OLA and its acidic degradation products relating the absorbances at the two selected wavelengths 296.3 and $271 \mathrm{~nm}$ to the corresponding concentrations of OLA and its acidic degradation products and the regression equations were computed.

Absorptivity coefficients of both OLA and its acidic degradation products were determined as shown in Table 1.

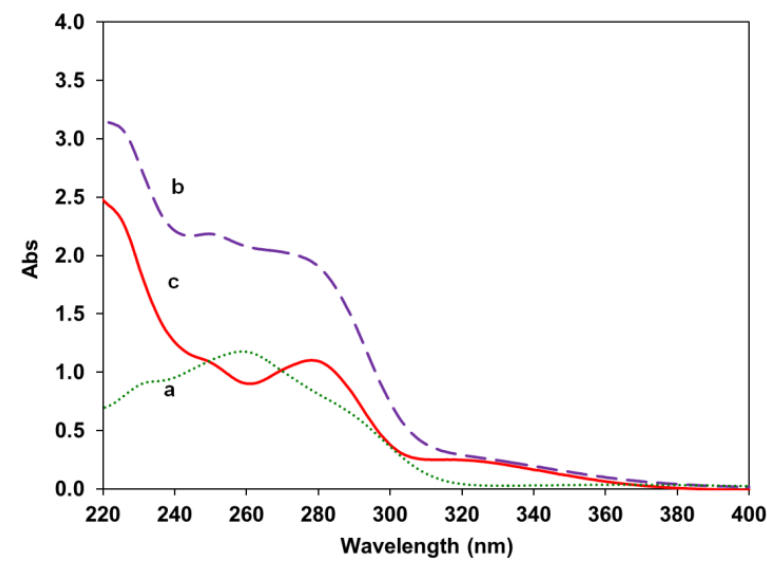

Figure 11. Zero-order absorption spectra of OLA (10 ug/mL), (a) in $0.1 \mathrm{M}$ $\mathrm{HCl}$ (...), (b) in $0.1 \mathrm{M} \mathrm{NaOH} \mathrm{(---),} \mathrm{(c)} \Delta \mathrm{A}$ spectra (__).

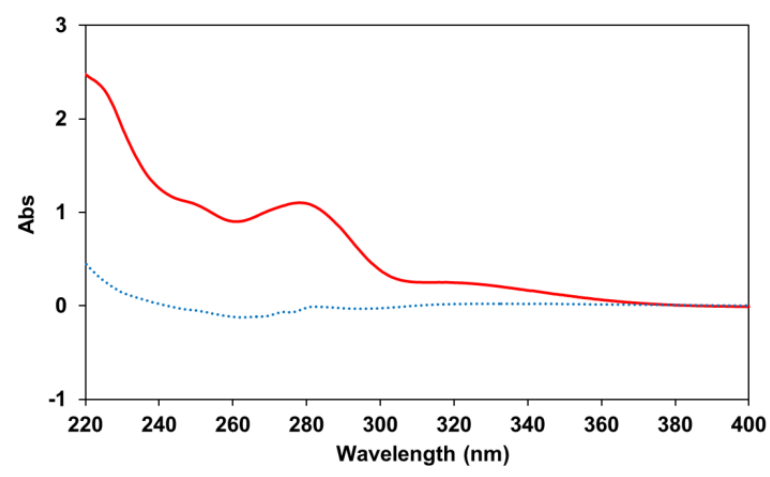

Figure 12. $\triangle \mathrm{A}$ spectra of OLA (__) and its acidic degradation products (...), in $0.1 \mathrm{M}$ (Hydrochloric acid and sodium hydroxide) (each, $10 \mathrm{ug} / \mathrm{mL}$ ).

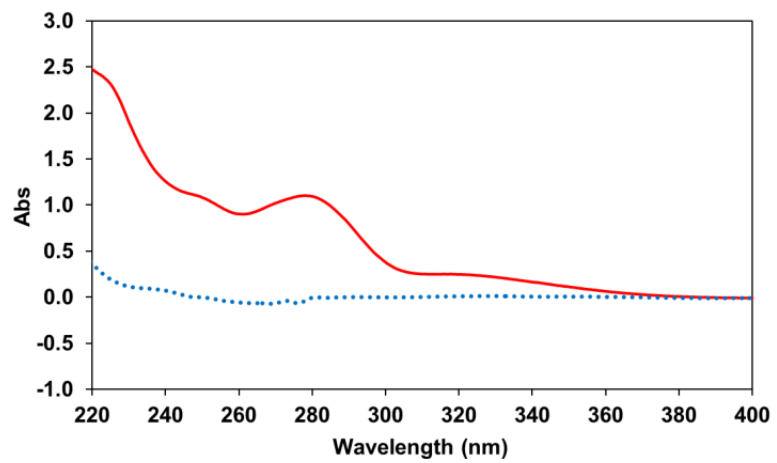

Figure 13. $\triangle \mathrm{A}$ spectra of OLA (__) and its alkaline degradation products (...), in $0.1 \mathrm{M}$ (hydrochloric acid and sodium hydroxide) (each, $10 \mathrm{ug} / \mathrm{mL}$ ).

The concentration of OLA was determined by substituting the absorbance and absorptivity coefficients in the following equation [65]. 
Table 1. Absorptivity coefficient values of Olanzapine and acidic degradation products at 296.3 (isosbestic point) and $271.0 \mathrm{~nm}\left(\lambda_{\max }\right.$ of OLA).

\begin{tabular}{|c|c|c|c|c|}
\hline \multirow[t]{2}{*}{ Sample no } & \multicolumn{2}{|c|}{ Absorptivity at $296.3 \mathrm{~nm}$} & \multicolumn{2}{|c|}{ Absorptivity at $271.0 \mathrm{~nm}$} \\
\hline & Olanzapine & Acidic deg. & Olanzapine & Acidic deg. \\
\hline$\overline{1}$ & 22.0 & 22.0 & 60.5 & 41.0 \\
\hline 2 & 22.5 & 21.5 & 60.7 & 40.5 \\
\hline 3 & 21.8 & 21.8 & 60.1 & 41.0 \\
\hline 4 & 22.1 & 21.8 & 60.2 & 41.0 \\
\hline 5 & 22.2 & 22.2 & 60.7 & 41.3 \\
\hline 6 & 21.7 & 21.9 & 60.0 & 41.0 \\
\hline Mean & 22.05 & 21.86 & 60.36 & 40.96 \\
\hline
\end{tabular}

Table 2. Application of the method of Kaiser for the selection of the wavelength set for the determination of olanzapine.

\begin{tabular}{|c|c|c|c|c|c|c|}
\hline$\lambda_{1} / \lambda_{2}$ & $215 \mathrm{~nm}$ & $229 \mathrm{~nm}$ & $245 \mathrm{~nm}$ & $262 \mathrm{~nm}$ & $271 \mathrm{~nm}$ & $300 \mathrm{~nm}$ \\
\hline $215 \mathrm{~nm}$ & 0 & 5.72 & 2.81 & 1.00 & 2.57 & 4.91 \\
\hline $229 \mathrm{~nm}$ & & 0 & 7.37 & 3.79 & 2.49 & 6.57 \\
\hline $245 \mathrm{~nm}$ & & & 0 & 3.15 & 4.54 & 3.09 \\
\hline $262 \mathrm{~nm}$ & & & & 0 & 1.27 & 4.39 \\
\hline $271 \mathrm{~nm}$ & & & & & 0 & 5.09 \\
\hline $300 \mathrm{~nm}$ & & & & & & 0 \\
\hline
\end{tabular}

$C_{O L A}=\frac{Q_{m}-Q_{y}}{Q_{X}-Q_{y}} \times \frac{A_{1}}{a_{x 1}}$

Where $A_{1}$ and $A_{2}$ are the absorbances of mixture at 296.3 and $271 \mathrm{~nm}$ respectively. $a_{x 1}$ and $a_{x 2}$ are the absorptivity coefficients of OLA at 296.3 and $271 \mathrm{~nm}$, respectively. While $a_{y 1}$ and $a_{y 2}$ are the absorptivity coefficients of acidic degradation products at 296.3 and $271 \mathrm{~nm}$, respectively. $\mathrm{Q}_{\mathrm{m}}$ $=\mathrm{A}_{2} / \mathrm{A}_{1}, \mathrm{Q}_{\mathrm{y}}=a_{y 2} / a_{y 1}$ and $\mathrm{Q}_{\mathrm{x}}=a_{x 2} / a_{x 1}$.

\subsection{Dual wavelength method}

The overlain spectrum of OLA and its acidic degradation products suggested that dual wavelength method is a suitable method for the simultaneous determination of OLA in presence of its degradation products [66].

From the overlain spectra, 270 and $246.3 \mathrm{~nm}$ were selected for the determination of OLA, where the acidic degradation products shows the same absorbances.

A linear Calibration curve was obtained in the range (0.002-0.02 $\mathrm{mg} / \mathrm{mL})$ relating the difference between the absorbances at the two selected wavelengths 270.0 and 246.3 $\mathrm{nm}$ to the corresponding drug concentrations in presence of acidic degradation products.

\subsection{Bivariate calibration method}

OLA was also determined and resolved from its acidic degradation products by using bivariate calibration spectrophotometric method [67].

This method is based on a simple mathematical algorithm, in which the data is used derives from four linear regression calibration equations, two calibrations for each component at two wavelengths selected using the method of Kaiser [68]. The method has been successfully applied to resolve different binary mixtures [69]. The advantage of bivariate calibration method is simplicity and the fact that derivatization procedure is not necessary. Unlike other chemometric techniques, there is no need for full spectrum information and no data processing is required.

The linear calibration regression function for the spectrophotometric determination of an analyte (A) at a selected wavelength (i) is given by $A_{A i}=m_{A i} C_{A}+e_{A i}$ where $m_{A i}$ is the slope of linear regression, $\mathrm{C}_{\mathrm{A}}$ is the concentration of analyte $A$ and $e_{A i}$ is the intercept value. If the measurement of the binary mixture (AB) are performed at two selected wavelengths $\left(\lambda_{1}, \lambda_{2}\right)$ we have two equations set [67]

$A_{A B 1}=m_{A 1} C_{A}+m_{B 1} C_{B}+e_{A B 1}$

$A_{A B 2}=m_{A 2} C_{A}+m_{B 2} C_{B}+e_{A B 2}$
The resolution of such equations set allows the evaluation of $C_{B}$ (concentration of OLA) and $C_{A}$ (concentration of acidic degradation products) from the following equations:

$C_{O L A}=\frac{m_{A 2}\left(A_{A B 1}-e_{A B 1}\right)+m_{A 1}\left(e_{A B 2}-A_{A B 2}\right)}{m_{A 2} m_{B 1}-m_{A 1} m_{B 2}}$

$C_{\text {degradate }}=\frac{A_{A B 1}-e_{A B 1}-m_{B 1} C_{O L A}}{m_{A 1}}$

These simple mathematical algorithms allows the resolution of the two components by measuring the absorbance of OLA and degradation products, each at two wavelengths and using the parameters of the linear regression functions evaluated individually for each component at the same wavelengths. The method of Kaiser [68] was used for the selection of optimum wavelength set which assured the best sensitivity for the quantitative determination of the studied drug.

In order to apply this method, the signals of the two components located at six wavelengths: $215,229,245,262$, 271, and $300 \mathrm{~nm}$ were selected.

The calibration curve equations and their respective linear regression coefficient were obtained directly with the aim of ensuring the linearity between the signal and the concentrations. The slope values of the linear regression were estimated for both the drug and its acidic degradation products at the selected wavelengths and used for the determination of the sensitivity matrices $K$, which proposed by Kaiser's method [68]. A series of sensitivity matrices, $K$, were created for every pair of pre-selected wavelengths.

$K=\left(\begin{array}{ll}m_{A 1} & m_{B 1} \\ m_{A 2} & m_{B 2}\end{array}\right)$

$A=$ Acidic degradate, $B=$ Olanzapine

where $m_{A 1,2}$ and $m_{B 1,2}$ are the sensitivity parameters (slope) of the regression equation of $A$ and $B$ at the two selected wavelengths $\left(\lambda_{1}\right.$ and $\left.\lambda_{2}\right)$. The determinants of these matrices were calculated as shown in Table 2 . The wavelength set was selected for which the highest matrix determinant value was obtained.

For bivariate determination of OLA in presence of its acidic degradation products, 229 and $245 \mathrm{~nm}$ wavelengths were used. Table 3 showed the linear regression calibration formula used for bivariate algorithm.

The laboratory prepared mixtures were analyzed by the proposed method for determination of intact OLA in presence of its acidic degradation products using the following equation

$C_{O L A}=\frac{m_{A 2}\left(A_{A B 1}-e_{A B 1}\right)+m_{A 1}\left(e_{A B 2}-A_{A B 2}\right)}{m_{A 2} m_{B 1}-m_{A 1} m_{B 2}}$ 
Table 3. Linear regression calibration formulas used for the bivariate algorithm.

\begin{tabular}{lll}
\multicolumn{1}{l}{ Component } & Calibration equations * & \\
\cline { 2 - 3 }$\lambda_{1}=229 \mathrm{~nm}$ & $\lambda_{1}=245 \mathrm{~nm}$ \\
\hline Olanzapine & $\mathrm{A}=0.0703 \mathrm{C}+0.0064 r=0.9998$ & $\mathrm{~A}=0.0503 \mathrm{C}-0.0032 r=0.9999$ \\
Acidic deg. & $\mathrm{A}=0.0439 \mathrm{C}-0.0035 r=0.9997$ & $\mathrm{~A}=0.0419 \mathrm{C}-0.0035 r=0.9997$ \\
\hline *
\end{tabular}

${ }^{*} \mathrm{~A}=$ Absorbance at the selected wavelength, $\mathrm{C}=$ Concentration in ug/mL; $r=$ Correlation coefficient.

Table 4. The concentration of mixtures of OLA, and its acidic degradate in the training set.

\begin{tabular}{lll}
\multicolumn{2}{l}{ Table 4. The concentration of mixtures of OLA, and its acidic degradate in the training set. } & Acidic degradation products (ug/mL) \\
\hline Sample no & Olanzapine (ug/ $\mathbf{m L})$ & 6 \\
1 & 6 & 2 \\
2 & 6 & 10 \\
3 & 2 & 4 \\
5 & 10 & 6 \\
6 & 10 & 4 \\
7 & 6 & 8 \\
8 & 4 & 10 \\
9 & 8 & 6 \\
10 & 8 & 10 \\
11 & 6 & 2 \\
12 & 10 & 8 \\
13 & 2 & 6 \\
14 & 2 & 8 \\
15 & 6 & 4 \\
16 & 8 & 4 \\
\hline
\end{tabular}

Table 5. The concentration of mixtures of OLA and its acidic degradation products in the validation set.

\begin{tabular}{lll} 
Sample no & Olanzapine $(\mathbf{u g} / \mathbf{m L})$ & Acidic deg. (ug/mL) \\
\hline 1 & 2 & 2 \\
2 & 4 & 10 \\
3 & 4 & 4 \\
4 & 10 & 8 \\
5 & 10 & 10 \\
6 & 8 & 2 \\
7 & 8 & 8 \\
9 & 4 & 2 \\
\hline
\end{tabular}

where $e_{A B 1}, e_{A B 2}$ are the sum of intercepts of the linear calibrations at the two wavelengths $\left(\mathrm{e}_{\mathrm{AB} 1}=\mathrm{e}_{\mathrm{A} 1}+\mathrm{e}_{\mathrm{B} 1}\right), 1,2$ are the wavelengths 229 and $245 \mathrm{~nm}, \mathrm{~m}_{\mathrm{A}}, \mathrm{m}_{\mathrm{B}}$ are the slopes of the linear regressions and $\mathrm{C}$ is the concentration of OLA.

\subsection{Multivariate method}

In this section, different chemometric approaches were applied for the determination of OLA in presence of its acidic degradation products, including CLS, PCR, PLS. These multivariate calibrations were useful in spectral analysis because the simultaneous inclusion of many spectral wavelengths instead of single wavelength greatly improved the precision and predictive ability [60].

The first step in the simultaneous determination of two components by multivariate calibration methods involves constructing the calibration matrix for binary mixture. The calibration set was obtained by using the absorption spectra of a set of 16 mixtures of OLA and its acidic degradation products with different ratios of each component and their concentrations are given in Table 4.

The model selected was that with the smallest number of factors such that RMSECV for the model was not significantly greater than RMSECV from the model with additional factor. As the difference between the minimum RMSECV and other RMSECV values became smaller, the probability that each additional factor was significant became smaller. Two factors were found to be suitable for both PLS and PCR methods.

The UV spectra of the prepared solutions were recorded over the range $240-370 \mathrm{~nm}$. Wavelengths (200-239 nm) dominated by noise and non-informative spectral region after $370 \mathrm{~nm}$ are not included. Spectra were digitized each at $0.1 \mathrm{~nm}$ interval, and the experimental data points were exposed to MATLAB version 7.0 for calculations.
To build the CLS model, feed the computer with absorbance and concentration matrices for training set. Carry out the calculations to obtain the "K" matrix. For the PCR and PLS models, use the training set absorbance and concentration matrices together with PLS-Toolbox 2.0 software for the calculations.

The selection of the optimum number of factors for the PLS technique was a very important step before constructing the models because if the number of factors retained was more than the required, more noise will be added to the data. On the other hand, if the number retained was too small meaningful data that could be necessary for the calibration might be discarded. In this study the leave one out cross validation method was used [70,71].

The root mean square error of prediction (RMSEP) was calculated as diagnostic tool for examining the errors in the predicted concentrations. It indicated both the precision and accuracy of predictions as it played the same role of standard deviation in indicating the spread of the concentration errors.

As the difference between the minimum RMSECV and other RMSECV values became smaller, the probability that each additional factor was significant became smaller. After the PCR and PLS models have been constructed, it was found that the optimum number of latent variables described by the developed models was two factors for PCR and PLS models.

Calibration graphs were constructed by plotting the predicted concentrations for OLA by each of the developed models versus the true concentrations. The statistical parameters of the linear relationship between the calculated and the true concentration of OLA in the calibration set were presented. In order to assess the predictive ability of each of the developed models, it was applied on an external validation set for determination of OLA.

Table 5 shows different concentrations of OLA and its acidic degradation products used in the validation set. 
Table 6. Validation parameters for the proposed stability-indicating spectrophotometric methods.

\begin{tabular}{|c|c|c|c|c|c|c|c|c|}
\hline \multirow{3}{*}{\multicolumn{2}{|c|}{ Validation parameters }} & \multicolumn{3}{|l|}{$\mathrm{D}^{\mathbf{n}}$} & \multicolumn{2}{|l|}{ DR $^{1}$} & \multicolumn{2}{|l|}{$\Delta \mathbf{A}$} \\
\hline & & $\overline{\mathbf{D}^{1}}$ & $\mathbf{D}^{1}$ & $\mathbf{D}^{2}$ & & & & \\
\hline & & $261.2 \mathrm{~nm}$ & $260.6 \mathrm{~nm}$ & $239.9 \mathrm{~nm}$ & $267.9 \mathrm{~nm}$ & $251.6 \mathrm{~nm}$ & $240 \mathrm{~nm}$ & $247.9 \mathrm{~nm}$ \\
\hline \multicolumn{2}{|c|}{ Linearity $(\mu \mathrm{g} / \mathrm{mL})$} & $2-20$ & $2-20$ & $2-20$ & $2-20$ & $2-20$ & $2-20$ & $2-20$ \\
\hline \multicolumn{2}{|c|}{ Slope } & 0.0559 & 0.0538 & 0.0206 & 0.0972 & 0.0600 & 0.1256 & 0.1108 \\
\hline \multicolumn{2}{|l|}{ Intercept } & -0.0006 & 0.0006 & 0.0001 & 0.0205 & -0.0040 & 0.0024 & 0.0022 \\
\hline \multicolumn{2}{|c|}{ Correlation coefficient (r) } & 0.9999 & 0.9999 & 0.9999 & 1 & 0.9999 & 0.9999 & 0.9999 \\
\hline \multicolumn{2}{|c|}{$\mathrm{LOD}(\mu \mathrm{g} / \mathrm{mL})$} & 0.08 & 0.09 & 0.11 & 0.25 & 0.34 & 0.229 & 0.259 \\
\hline \multicolumn{2}{|c|}{$\mathrm{LOQ}(\mu \mathrm{g} / \mathrm{mL})$} & 0.25 & 0.29 & 0.35 & 0.75 & 1.05 & 0.695 & 0.785 \\
\hline \multirow[t]{2}{*}{ Precision } & Intra-day a & 1.27 & 0.15 & 0.13 & 0.16 & 0.06 & 0.92 & 0.84 \\
\hline & Inter-day ${ }^{\mathrm{b}}$ & 1.04 & 0.29 & 0.21 & 0.26 & 0.31 & 0.61 & 0.50 \\
\hline \multirow{2}{*}{\multicolumn{2}{|c|}{ Validation parameters }} & \multicolumn{3}{|c|}{ Q-Analysis method } & \multicolumn{2}{|c|}{ Dual wave length method } & \multicolumn{2}{|c|}{ Bivariate calibration method } \\
\hline & & $296.3 \mathrm{~nm}$ & $271 \mathrm{~nm}$ & & \multicolumn{2}{|c|}{$247.9 \mathrm{~nm}$} & $229 \mathrm{~nm}$ & $245 \mathrm{~nm}$ \\
\hline \multicolumn{2}{|c|}{ Linearity $(\mu \mathrm{g} / \mathrm{mL})$} & $2-20$ & $2-20$ & & \multicolumn{2}{|l|}{$2-20$} & $2-20$ & $2-20$ \\
\hline \multicolumn{2}{|c|}{ Slope } & 0.2196 & 0.0602 & & \multicolumn{2}{|l|}{0.0102} & 0.0703 & 0.0502 \\
\hline \multicolumn{2}{|l|}{ Intercept } & 0.00053 & 0.0010 & & \multicolumn{2}{|l|}{-0.0022} & 0.0064 & -0.0032 \\
\hline \multicolumn{2}{|c|}{ Correlation coefficient (r) } & 0.9998 & 0.9999 & & \multicolumn{2}{|l|}{0.9998} & 0.9998 & 0.9999 \\
\hline \multicolumn{2}{|c|}{$\mathrm{LOD}(\mu \mathrm{g} / \mathrm{mL})$} & 0.369 & 0.158 & & \multicolumn{2}{|l|}{0.277} & 0.4642 & 0.2557 \\
\hline \multicolumn{2}{|c|}{$\mathrm{LOQ}(\mu \mathrm{g} / \mathrm{mL})$} & 1.119 & 0.481 & & \multicolumn{2}{|l|}{0.839} & 1.4066 & 0.7749 \\
\hline \multirow[t]{2}{*}{ Precision } & Intra-day a & 1.19 & & & \multicolumn{2}{|l|}{0.12} & \multicolumn{2}{|l|}{0.46} \\
\hline & Inter-day ${ }^{\mathrm{b}}$ & 0.98 & & & \multicolumn{2}{|l|}{0.67} & \multicolumn{2}{|l|}{0.62} \\
\hline
\end{tabular}

The intraday $(\mathrm{n}=3)$ average of three concentrations $(6,10$, and 14$)$ repeated three times within day.

${ }^{\mathrm{b}}$ The interday $(\mathrm{n}=9)$ average of three concentrations repeated three times in three successive days.

Table 7. Results of assay validation obtained by applying the proposed chemometric methods for the determination of Olanzapine in presence of its acidicdegradation products.

Validation parameters

Predicted versus actual concentration plot

Slope

Intercept

Correlation coefficient $(r)$

RMSEP

\begin{tabular}{lll} 
CLS & PCR & PLS \\
0.9995 & & \\
0.0023 & 1.0051 & 0.9995 \\
1.0000 & 0.0194 & 0.0024 \\
0.0035 & 0.9999 & 1.0000 \\
& 0.0318 & 0.0036 \\
\hline
\end{tabular}

Table 8. Determination of the studied drug in the laboratory prepared (L.P.) mixtures with its degradation products and in tablets by the proposed methods

\begin{tabular}{|c|c|c|c|c|c|c|c|c|}
\hline \multirow[t]{3}{*}{ Sample } & \multicolumn{3}{|l|}{$D^{n}$-method a } & \multicolumn{2}{|c|}{ DR $^{1}$-method a } & \multicolumn{3}{|l|}{$\Delta$ A-method a } \\
\hline & $\overline{D^{1}}$ & $\mathbf{D}^{1}$ & $\mathrm{D}^{2}$ & & & & & \\
\hline & $261.2 \mathrm{~nm}$ & $260.6 \mathrm{~nm}$ & $239.9 \mathrm{~nm}$ & $267.9 \mathrm{~nm}$ & $251.6 \mathrm{~nm}$ & $240 \mathrm{~nm}$ & \multicolumn{2}{|c|}{$247.9 \mathrm{~nm}$} \\
\hline \multirow{2}{*}{$\begin{array}{l}\text { L.P.-mixtures } \\
(\mathrm{n}=5)^{\mathrm{b}}\end{array}$} & $100.49 \pm 0.32$ & $100.93 \pm 0.63$ & $100.93 \pm 0.63$ & $99.86 \pm 0.09$ & $100.80 \pm 0.38$ & $99.86 \pm 0.17$ & 99.5 & 0.38 \\
\hline & \multicolumn{8}{|c|}{ Up to $60 \%$ degradation } \\
\hline $\begin{array}{l}\text { Olanza tablets } 5 \mathrm{mg} \text {, } \\
\text { B.N.1821007 }\end{array}$ & $100.50 \pm 1.41$ & $99.90 \pm 0.48$ & $99.96 \pm 0.32$ & $99.98 \pm 0.30$ & $100.65 \pm 0.60$ & $100.73 \pm 0.65$ & \multicolumn{2}{|c|}{$99.64 \pm 0.89$} \\
\hline Sample & $\begin{array}{l}\text { Q-Analysis } \\
\text { method a }\end{array}$ & \multicolumn{2}{|c|}{$\begin{array}{l}\text { Dual wave length } \\
\text { method a }\end{array}$} & \multicolumn{2}{|c|}{$\begin{array}{l}\text { Bivariate calibration } \\
\text { method a }\end{array}$} & CLS a & PCR a $^{\text {a }}$ & PLS a \\
\hline \multirow{2}{*}{$\begin{array}{l}\text { L.P.-mixtures } \\
(\mathrm{n}=5)^{\mathrm{b}}\end{array}$} & $99.96 \pm 0.13$ & \multicolumn{2}{|l|}{$101.47 \pm 0.67$} & \multicolumn{2}{|l|}{$100.97 \pm 0.13$} & $99.98 \pm 0.08$ & $100.10 \pm 0.32$ & $100.01 \pm 0.08$ \\
\hline & \multicolumn{5}{|c|}{ Up to $60 \%$ degradation } & \multicolumn{3}{|c|}{ Up to $50 \%$ degradation } \\
\hline $\begin{array}{l}\text { Olanza tablets } 5 \mathrm{mg} \text {, } \\
\text { B.N.1821007 }\end{array}$ & $100.64 \pm 1.08$ & $99.72 \pm 1.06$ & & $100.87 \pm 1.38$ & & $99.96 \pm 0.32$ & $99.90 \pm 0.48$ & $100.50 \pm 1.41$ \\
\hline
\end{tabular}

Recovery \pm RSD.

b Sets each of 3 replicates.

Table 9. Application of the standard addition technique to the analysis of the studied drug by the proposed methods.

\begin{tabular}{|c|c|c|c|c|c|c|c|c|}
\hline \multirow{3}{*}{$\begin{array}{l}\text { Pharmaceutical } \\
\text { preparation }\end{array}$} & \multirow{3}{*}{$\begin{array}{l}\text { Authentic } \\
\text { added } \\
\text { (ug/mL) }\end{array}$} & \multicolumn{7}{|c|}{ Standard addition, Recovery $\% * *$} \\
\hline & & \multicolumn{2}{|c|}{$\mathbf{D}^{1}$} & \multirow{2}{*}{$\begin{array}{l}D^{2} \\
239.90 \mathrm{~nm}\end{array}$} & \multicolumn{2}{|l|}{ DR $^{1}$} & \multicolumn{2}{|l|}{$\Delta \mathbf{A}$} \\
\hline & & $261.20 \mathrm{~nm}$ & $260.60 \mathrm{~nm}$ & & $267.9 \mathrm{~nm}$ & $251.6 \mathrm{~nm}$ & $240 \mathrm{~nm}$ & $247.9 \mathrm{~nm}$ \\
\hline${\text { Olanza }{ }^{\circledR} \text { tablets* }}^{*}$ & 2 & 99.47 & 98.54 & 98.57 & 100.41 & 101.49 & 99.69 & 100.61 \\
\hline $5 \mathrm{mg}$ & 4 & 102.95 & 99.89 & 99.35 & 100.20 & 101.08 & 101.25 & 99.94 \\
\hline \multirow[t]{13}{*}{ B.N. 1821007} & 6 & 99.64 & 99.83 & 99.93 & 99.79 & 100.11 & 101.34 & 99.12 \\
\hline & 8 & 100.22 & 100.58 & 100.58 & 99.71 & 100.24 & 100.58 & 98.37 \\
\hline & 10 & 100.21 & 99.83 & 100.37 & 99.77 & 100.33 & 100.77 & 100.17 \\
\hline & Mean & 100.50 & 99.90 & 99.96 & 99.98 & 100.65 & 100.73 & 99.64 \\
\hline & SD & 1.41 & 0.48 & 0.32 & 0.30 & 0.60 & 0.65 & 0.89 \\
\hline & $\begin{array}{l}\text { Authentic } \\
\text { added } \\
\text { (ug/mL) }\end{array}$ & $\begin{array}{l}\text { Q-Analysis } \\
\text { method }\end{array}$ & $\begin{array}{l}\text { Dual wave } \\
\text { length method }\end{array}$ & \multicolumn{2}{|c|}{$\begin{array}{l}\text { Bivariate calibration } \\
\text { method }\end{array}$} & CLS & PCR & PLS \\
\hline & 2 & 99.46 & 101.50 & \multicolumn{2}{|l|}{102.09} & 99.47 & 99.54 & 98.57 \\
\hline & 4 & 100.78 & 98.71 & \multicolumn{2}{|l|}{102.29} & 102.95 & 99.89 & 99.35 \\
\hline & 6 & 99.64 & 99.77 & \multicolumn{2}{|l|}{99.01} & 99.64 & 99.83 & 99.93 \\
\hline & 8 & 102.03 & 99.42 & \multicolumn{2}{|l|}{100.91} & 100.22 & 100.58 & 100.58 \\
\hline & 10 & 101.28 & 99.19 & \multicolumn{2}{|l|}{100.06} & 100.21 & 99.83 & 100.37 \\
\hline & Mean & 100.64 & 99.72 & \multicolumn{2}{|l|}{100.87} & 100.50 & 99.90 & 99.96 \\
\hline & SD & 1.08 & 1.06 & \multicolumn{2}{|l|}{1.38} & 1.41 & 0.48 & 0.32 \\
\hline
\end{tabular}

\footnotetext{
** Average of at least 3 separate determinations.
} 
Table 10. Statistical comparison of the results obtained by the proposed methods and the reported method for the determination of Olanzapine in pharmaceutical preparation.

\begin{tabular}{|c|c|c|c|c|c|c|c|}
\hline \multirow[t]{2}{*}{ Items } & \multicolumn{2}{|l|}{$\underline{\mathbf{D}^{1}}$} & \multirow{2}{*}{$\begin{array}{l}D^{2} \\
239.90 \mathrm{~nm}\end{array}$} & \multicolumn{2}{|l|}{ DR $^{1}$} & \multicolumn{2}{|l|}{$\Delta \mathbf{A}$} \\
\hline & $261.20 \mathrm{~nm}$ & $260.60 \mathrm{~nm}$ & & $267.9 \mathrm{~nm}$ & $251.6 \mathrm{~nm}$ & $240 \mathrm{~nm}$ & $247.9 \mathrm{~nm}$ \\
\hline Mean & 100.46 & 100.47 & 100.36 & 99.54 & 99.27 & 100.10 & 99.99 \\
\hline SD & 0.291 & 0.301 & 0.32 & 0.315 & 0.194 & 0.521 & 0.510 \\
\hline RSD $\%$ & 0.289 & 0.300 & 0.32 & 0.315 & 0.194 & 0.521 & 0.510 \\
\hline $\mathrm{n}$ & 5 & 5 & 5 & 5 & 5 & 5 & $\underline{5}$ \\
\hline Variance & 0.084 & 0.091 & 0.102 & 0.099 & 0.038 & 0.271 & 0.260 \\
\hline Student's $t$-test (2.306) & 0.04 & 0.06 & 0.49 & 0.915 & 1.060 & 1.29 & 1.72 \\
\hline F-test (6.388) & 1.07 & 1.00 & 1.37 & 1.090 & 2.39 & 2.97 & 2.85 \\
\hline Items & $\begin{array}{l}\text { Q-analysis } \\
\text { method }\end{array}$ & $\begin{array}{l}\text { Dual wave } \\
\text { length method }\end{array}$ & $\begin{array}{l}\text { Bivariate calibration } \\
\text { method }\end{array}$ & CLS & PCR & PLS & $\begin{array}{l}\text { Reported } \\
\text { method * }\end{array}$ \\
\hline Mean & 100.70 & 100.38 & 100.71 & 99.96 & 100.02 & 99.97 & 100.45 \\
\hline SD & 0.492 & 0.231 & 0.350 & 0.360 & 0.371 & 0.362 & 0.302 \\
\hline RSD\% & 0.489 & 0.230 & 0.347 & 0.360 & 0.371 & 0.362 & 0.300 \\
\hline $\mathrm{n}$ & 5 & 5 & 5 & 5 & 5 & 5 & 5 \\
\hline Variance & 0.242 & 0.056 & 0.123 & 0.129 & 0.137 & 0.131 & 0.091 \\
\hline Student's $t$-test (2.306) & 0.95 & 0.116 & 1.22 & 2.29 & 2.03 & 2.29 & \\
\hline F-test $(6.388)$ & 2.70 & 1.63 & 1.35 & 1.41 & 1.50 & 1.43 & \\
\hline
\end{tabular}

The values between parenthesis are the theoretical values of $t$-test and F-test at $p=0.05$.

* Direct derivative Spectrophotometric method where the first derivative values were measured at $222 \mathrm{~nm}$ in methanol [16].

To validate the prediction ability of the suggested models, they were used to predict the concentration of OLA in laboratory prepared mixtures containing different ratios of them.

Results of assay validation obtained by applying the proposed spectrophotometric and chemometric methods for the determination of Olanzapine in presence of its degradation products are presented in Tables 6 and 7, respectively.

The proposed methods were applied successfully to analysis of OLA in pharmaceutical formulation, and the results obtained were listed in Table 8.

Standard addition technique was successfully applied for the analysis of the studied drug by the proposed methods and results are presented in Table 9.

Table 10 represents statistical comparison of the results obtained by the proposed methods and the reported method for the determination of OLA in pharmaceutical preparation.

\section{Conclusion}

The proposed methods are simple, very sensitive, precise, and can be easily applied in QC laboratories for determination of OLA in presence of its acidic and alkaline degradation products. The proposed methods could be also successfully applied for routine analysis of OLA either in its bulk powder or in dosage form in QC laboratories, without any preliminary separation step.

\section{References}

[1]. David, B.; Beringer, P. Remington: The Science and Practice of Pharmacy, 21 ${ }^{\text {th }}$ Edition, Lippincott Williams \& Wilkins, 2006.

[2]. Nagaraju, K. B.; Kanakapura, R.; Vinay, B. Chem. Ind. Chem. Eng. $Q$ 2009, 15(2), 77-81.

[3]. Basavaiah, K.; Abdulrahman, S. M. Int J. Chem. Tech. Res. 2010, 2(1), 660-680.

[4]. Firdous, S.; Aman, T.; Nisa, A. J. Chem. Soc. Pakistan 2005, 27(2), 163167.

[5]. Basavaiah, K.; Tharpa, K.; Ragendraprasad, N.; Hiriyanna, S. G.; Vinay, K. B. Jordan J. Chem. 2009, 4(1), 65-76.

[6]. Basavaiah, K.; Abdulrahman, S. M.; Vina,y K. B. J. Food Drug Anal. 2009, 17(6), 434-442.

[7]. Ragendraprasad, N.; Basavaiah, K. Braz. J. Pharm. Sci. 2009, 45(3), 539-550.

[8]. Basavaiah, K.; Zenita, O.; Tharpa, K.; Rajendraprasad, N.; Anilkumar, U. R.; Hiriyana, S. G.; Vinay, K. B. Chem. Ind. Chem. Eng. Q 2009, 15(2), 95102.

[9]. Revanasiddappa, H. D.; Veena, M. A. Eclet. Quim. 2008, 33(3), 47-52.

[10]. Rajendraprasad, N.; Basavaiah, K. J. Anal. Chem. 2010, 65(5), 482-488.

[11]. Krebs, A.; Starczewska, B.; Tarasiewicz, H.; Sled, P. J. Anal. Sci. 2006, 22(6), 829-833.

[12]. Mohamed, A. Chem. Mater. Sci. 2008, 139(9), 1005-1010.

[13]. Jasinska, A.; Nalewajko, E. Anal. Chim. Acta 2004, 508(2), 165-170.
[14]. Basavaiah, K.; Abdulrahman, S. M.; Vinay, K. B. Jordan J. Chem. 2010, 5(1), 101-117.

[15]. Rajendraprasad, N.; Basavaiah, K.; Tharpa, K.; Vinay, K. B. Eurasian J. Anal. Chem. 2009, 4(2), 191-203.

[16]. Patel, V. M.; Patel, J. A.; Havele, S. S.; Dhaneshwar, S. R. Int. J. Chem. Tech. Res. 2010, 2(1), 756-761.

[17]. Biryol, I.; Erk, N. Anal. Lett. 2003, 36(11), 2497-2513.

[18]. Raggi, M. A.; Casamenti, G.; Mandrioli, R.; Izzo, G.; Kenndler, E. J. Pharmaceut. Biomed. 2000, 23(6), 973-981.

[19]. Belal, F.; El-Brashy, A.; El-Enany, N.; El-Bahay, N. J. AOAC Int. 2008, 91(6), 1309-1317.

[20]. Patel, S.; Patel, N. J. Indian J. Pharm. Sci. 2009, 71(4), 477-480.

[21]. Shah, C. R.; Shah, N. J.; Suhagia, B. N.; Patel, N. M. J. AOAC Int. 2007 90(6), 1573-1578.

[22]. Patel, K. S.; Patel, N. J.; Patel, U. P.; Patel, B. D.; Patel, A. S.; Prajapati, M. U. J. Planar Chrom. 2009, 22(2), 121-126.

[23]. Saxena, V.; Zaheer, Z.; Farooqui, M. Asian J. Chem. 2006, 18(2), 12121222.

[24]. Shah, C. R.; Suhagia, B. N.; Shah, N. J.; Patel, D. R.; Patel, N. M. Indian J. Pharm. Sci. 2008, 70(2), 251-255.

[25]. Mohammadi, A.; Amini, M.; Hamedani, M. P.; Torkabadi, H. H.; Walker, R. B. Asian J. Chem. 2008, 20(7), 5573-5580.

[26]. Saracino, M. A.; Gandolfi, O.; Dall'Olio, R.; Albers, L.; Kenndler, E.; Raggi, M. A. J. Chromatogr. A 2006, 1122(1-2), 21-27.

[27]. Zhang, G.; Terry, A. V.; Bartlett, M. G. J. Chromatogr. B 2007, 858(1-2), 276-281.

[28]. Ole, V. O.; Linnet, K.; Kristian, D. L. J. Chromatogr. B 1998, 714(2), 309 315.

[29]. Tang, Y.; Song, W.; Wu, L. Zhogguo Yaoye 2007, 16(21), 46-47.

[30]. Xia, Y.; Jiang, K.; Wu, A.; Li, H. Zhongguo Yaoxue Zazhi 2002, 37(3), 215-217.

[31]. D'Arrigo, C.; Migliardi, G.; Santoro, V. Ther. Drug Monit. 2006, 28(3), 388-393.

[32]. Titier, K.; Bouchet, S.; Pehourcq, F.; Moore, N.; Molimard, M. J. Chromatogr. B 2003, 788(1), 179-185.

[33]. Kobylinska, K.; Bus, K. M.; Kiliszek, M. B. Acta Pol. Pharm. 2008, 65(6), 759-762.

[34]. Aravagiri, M.; Teper, Y.; Marder, R. Biopharm. Drug Dispos. 1999 20(8), 369-377.

[35]. Dusci, J. L.; Hackett, L. P.; Fellows, L. M.; Ilett, K. F. J. Chromatogr. B 2002, 773(2), 191-197.

[36]. Raggi, M. A.; Mandrioli, R.; Sabbioni, C.; Ghedini, N.; Fanali, S.; Volterra, V. Chromatographia 2001, 54(3-4), 203-207.

[37]. Llorca, M. P.; Coudore, F.; Corpelet, C.; Buyens, A.; Hoareau, M.; Eschalie,r A. Fr. Clinical Chemistry 2001, 47(9), 1719-1721.

[38]. Berna, M.; Ackermann, B.; Ruterbories, K.; Glass, S. J. Chromatogr. B 2002, 767(1), 163-168.

[39]. Saracino, M. A.; Gandolfi, O.; Dall'Olio, R.; Albers, L.; Kenndler, E.; Raggi M. A. J. Chromatogr A 2006, 1122(1-2), 21-27.

[40]. Josefsson, M.; Roman, M.; Skogh, E.; Dahl, M. J. Pharmaceut. Biomed. 2010, 53(3), 576-582.

[41]. Kasper, C.; Mattiuz, E. L.; Swanson, S. P.; Chiu, J. A.; Johnson, J. T. Garnera, C. O. J. Chromatogr B, 1999, 726(1-2), 203-209.

[42]. Rao, R. N.; Raj, A. N.; Narsimha, R.; Babu, G. B. J. Sep. Sci. 2008, 31(1), 107-118.

[43]. Rani, P.; Sekaran, B. Int. J. Pharm. Tech. Res. 2009, 1(3), 654-657.

[44]. Basavaiah, K.; Rangachar, A. K. U.; Tharpa, K. J. Mex. Chem. Soc. 2008 52(2), 120-124.

[45]. Rani, A. P.; Sekaran, C. B. Int. J. Pharm. Tech. Res. 2009, 1(3), 654-657. 
[46]. Reddy, B. V.; SureshReddy, K. V.; Sreeramulu, J.; Kanumula, G. V. Chromatographia 2007, 66(1-2), 111-114.

[47]. Weigmann, H.; Hartter, S.; Maehrlei, S.; Kiefer, W.; Kräamer, G.; Dannhardt, G.; Hiemke, C. J. Chromatogr. B 2001, 759(1), 63-71.

[48]. Zhang, G.; Terry, A. V.; Bartlett, M. G. J. Chromatogr, B 2007, 856(1-2), 20-28.

[49]. Sachsea, J.; Kollerb, J.; Haertter, S.; Hiemke, C. J. Chromatogr. B 2006, 830(2), 342-348.

[50]. Li, W.; Zhai, Y.; Wang, C.; Qin, Y.; Weng Y. Sepu 2000, 18(6), 550-553.

[51]. Bogusz, M. J.; Kruger, K. D.; Maier, R. D.; Erkwoh, R. J. Chromatogr. B 1999, 732(2), 257-269.

[52]. Zhou, Z.; Li, X.; Li, K.; Xie, Z.; Cheng, Z.; Peng, W.; Wang, F.; Zhu, R.; Li, H. J. Chromatogr. B 2004, 802(2), 257-262

[53]. Pathak, A.; Rajput, S. J. J. Chromatogr. Sci. 2009, 47(7), 605-611.

[54]. Harvey, E. J.; Flanagan, R. J.; Taylor, D. M. Pharm. J. 2000, 265(70), 275-276.

[55]. Rao, P. S.; Ray, U. K.; Hiriyanna, S. G.; Rao, S. V.; Sharma, H. K.; Handa, V. K.; Mukkanti, K. J. Pharmaceut. Biomed. 2011, 56(2), 413-418.

[56]. Krishnaiaha, C.; Murthya, M. V.; Kumara, R.; Mukkantib, K. J. Pharmaceut. Biomed. 2011, 54, 667-673.

[57]. Hiriyanna, S. G.; Basavaiah ,K.; Goud, P. S. K.; Dhayanith, V.; Raju, K.; Pati, H. N. Acta Chromatogr. 2008, 20(1), 81-93.

[58]. Jenkins, A. J.; Sarconi, K. M.; Raaf, H. N. J. Anal Toxicol. 1988, 22(7), 605-609.

[59]. Suslu, I.; Altınoz, S.; Erdal, D.; Baleanu, D. Int. Works. New Trends Sci. Tech. November, 2008, Ankara, Turkey, http://ntst08.cankaya.edu.tr/proceedings/proceedings/IncilaySusluP aper.pdf , Online: 02/17/2014

[60]. Ni, Y.; Gong, X. Anal. Chim. Acta 1997, 354, 163-171.

[61]. ICH, Q2 (R1), Validation of Analytical Procedures: Text and Methodology. International Conference on Harmonization, Geneva, Switzerland 2005

[62]. Salinas, F.; Berzas, J. J.; Espinosa, M. A. Talanta 1990, 37(3), 347- 351.

[63]. Shevchenko, V. P.; YuNagaev, I.; Kost, N. V.; Ivanov, I. A. Dokl. Chem. 2010, 434, 260-262.

[64]. Chitlange, S. S.; Ranjana, S.; Wankhede, S. B.; Kulkarni, A. A. Int. J. Chem. Tech Res. 2009, 1(2), 135-138.

[65]. Dhabale, P. N.; Bhagade, S. R. J. Chem. Pharm. Res. 2011, 3(2), 650-656.

[66]. Fernandes, N.; Nimdeo, M. S.; Choudhari, V. P.; Kulkarni, R. R.; Pande V.; Nikalje, A. G. Int. J. Chem. Sci. 2008, 6(1), 29-35.

[67]. Lopez-Martinez, L.; Lopez-de-Alb, P. L.; Creda-Martin, V. Anal. Lett. 2001, 34(14), 2563- 2583.

[68]. Massart, D. L.; Vandeginsite, B. G. M.; Deming, S. N.; Michotte, Y.; Kaufman, L. Chemometrics: a textbook, El-Servier , Amsterdam, 1988.

[69]. Lopez-de-Alba, P. L.; Wrobel, K.; Lopez-Martinez, L.; Yepez-Murrieta, M. L.; Amador-Hernandez, J. J. Pharmaceut. Biomed. 1997, 16, 349-355

[70]. Haaland, D. M.; Thomas, E. V. Comparison of multivariate calibration methods for quantitative spectral analysis. Anal. Chem. 1990, 62, 1091-1099.

[71]. Kenneth, R. B.; Randy, J. P.; Seasholtz, M. B. Chemometrics: A Practical Guide, New York: John Wiley and Sons Inc. 1998. 